\title{
Surgical Stabilization of the Extensor Tendon Dislocation in Non-Rheumatic Hand
}

\author{
Ricardo Monreal ${ }^{1 *}$ and Giovanni Osinaga ${ }^{2}$ \\ ${ }^{1}$ Medica Vial Orthopedic Clinic, Alvaro Obregon No.151, Mexico City, Mexico \\ ${ }^{2}$ Hospital Obrero No. 3, Caja Nacional de Salud, Department of Orthopaedics, Santa Cruz, Bolivia
}

Submission: August 05, 2019; Published: September 13, 2019

*Corresponding author: Ricardo Monreal, Medica Vial Orthopedic Clinic, Alvaro Obregon No.151, Mexico City, Mexico

\section{Abstract}

Purpose: Treatment of traumatic sagittal band injury and subluxation of the extensor tendon at the metacarpophalangeal joint is often conservative but can also require surgical intervention if conservative treatment fails. A technique is presented using an extensor digitorum communis (EDC) tendon slip to stabilize the dislocated extensor tendon.

Methods: Nine patients ( 7 males and 2 females) with persistent pain and traumatic or spontaneous extensor tendon subluxations ( $>6$ weeks) in non-rheumatic hand underwent surgery.

Results: In all patients the EDC tendon demonstrated pain-free stability without subluxation on metacarpophalangeal joint flexion, with a full range of motion (ROM) of the metacarpophalangeal (MCP) joint.

Conclusion: Restoration of sagittal band stability and extensor tendon centralization at the metacarpophalangeal joint by the extensor slip loop technique recreate the physiologic biomechanical forces.

Keywords: Sagittal band; Extensor tendon subluxation, Reconstruction

\section{Introduction}

Different etiologies of extensor tendons dislocation of the hand (degenerative, traumatic, spontaneous and congenital) are mentioned although this condition is a is relatively uncommon in non-rheumatic hand [1,2].

Ulnar dislocation of the extensor tendon is the result of failure of the sagittal band to centralize the tendon, usually occurs in the middle finger because the radial component of the sagittal band is more prone to injury because they are thinner and longer than the ulnar fibers $[3,4]$. When dislocation of the extensor tendon is not treated in acute phase by closed methods, extensor tendon instability persists, and surgical treatment is indicated. A simple surgical technique is presented using an extensor digitorum communis (EDC) tendon slip to stabilize the dislocated extensor tendon.

\section{Material and Methods}

Nine patients ( 7 males and 2 females) with persistent pain and traumatic or spontaneous extensor tendon subluxations (> 6 weeks) in non-rheumatic hand (Figure 1) underwent surgery. Joint contracture and arthritic deformity were considered contraindications. The mean age was 28.6 years (range, 16-47 years). The middle finger was involved in all patients. The causes included traumatic subluxation ( 7 cases) and spontaneous subluxation ( 2 cases). The period from acute rupture of the sagittal bands and extensor tendon dislocation to surgery was a mean of 10.8 months (range, 3-18 months). Informed consent from the patients were obtained for this study. This study conforms to the Declaration of Helsinki.

\section{Assessment of the Pre- and Postoperative findings}

The involved finger was pre- and postoperatively evaluated on the basis of the symptoms including pain on metacarpophalangeal joint flexion associated with dislocation of the extensor tendon (Figure 1), and the range of motion (ROM) of the metacarpophalangeal (MCP) joint. The necessary range of motion (ROM) of the metacarpophalangeal (MCP) joints to maintain hand function are flexion $\mathrm{ROM}>70^{\circ}$ with an extension $\mathrm{ROM}<30^{\circ}$ of extension lag [5].

\section{Surgical Technique [6]}

The ulnar dislocated extensor tendon is exposed using a dorsal 3-cm curved incision over the metacarpophalangeal joint. A distally based extensor digitorum communis (EDC) tendon strip $1 / 3$ width on same side of tear is looped around the EDC to prevent migration of slip (1st. loop), passed under the deep transverse intermetacarpal ligament (DTML) on the radial side 


\section{Orthopedics and Rheumatology Open Access Journal (OROAJ)}

(2nd. loop) and woven back to into extensor hood / remaining EDC tendon and sutured after adjusting the tension. In the cases involving the index finger the tendon slip was passed under the radial lateral band instead of the deep transverse intermetacarpal ligament (Figure 2).
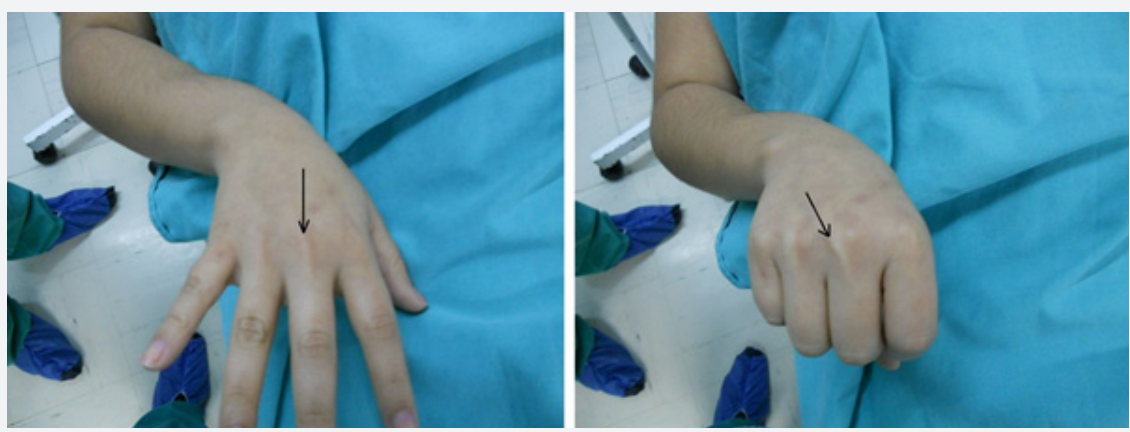

Figure 1: Preoperative photograph: ulnar subluxation of the extensor tendon over the MCP joint with active flexion of the right middle finger (black arrows).
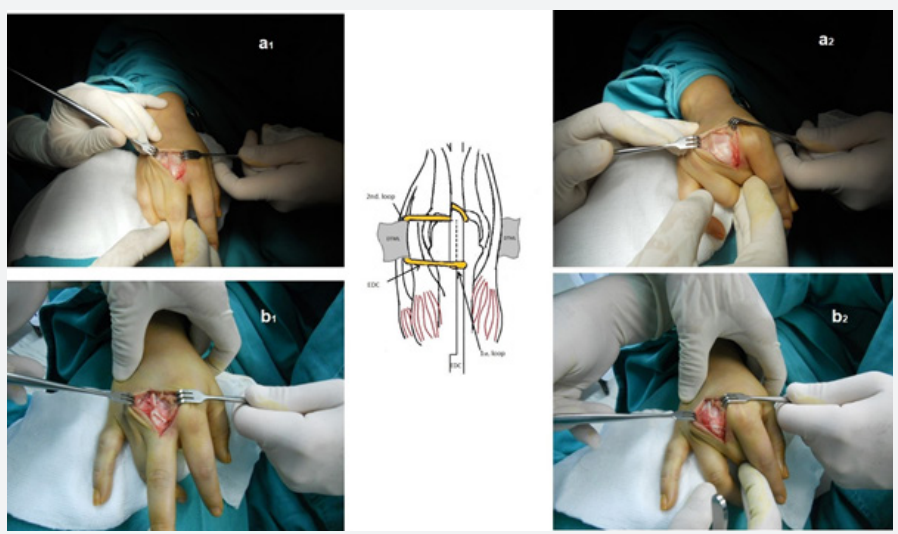

Figure 2: Trans operative photograph: ulnar subluxation of the extensor tendon from extension (a1) to flexion (a2). Centralization and stabilization of the extensor tendon from extension (b1) to flexion (b2).

\section{Postoperative Rehabilitation}

After surgery, the arm is maintained with a short orthosis for 6 weeks with the metacarpophalangeal and proximal interphalangeal joints extended allowing active range of motion of the distal interphalangeal joint is allowed. When the shortarm orthosis is removed, the patient begins active motion of the metacarpophalangeal and proximal interphalangeal joints.

\section{Results}

In all patients the EDC tendon demonstrated pain-free stability without subluxation on metacarpophalangeal joint flexion, with a full range of motion (ROM) of the metacarpophalangeal (MCP) joint at the latest postoperative evaluation $(9$ months) (Figure 3) (Table 1).

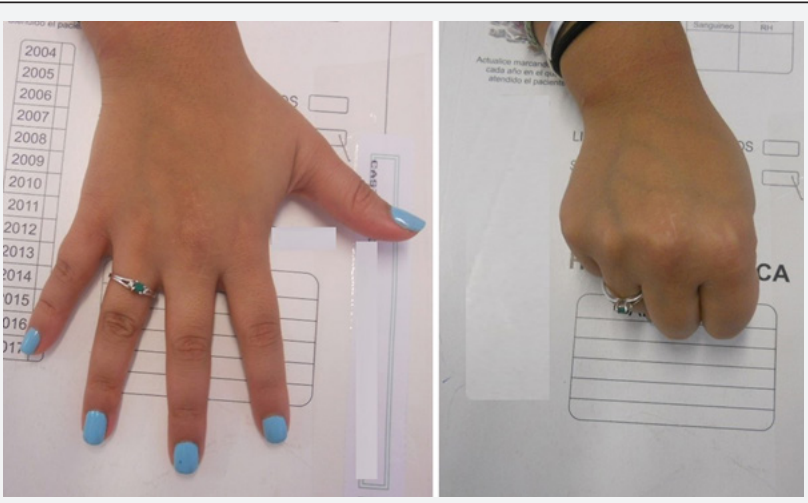

Figure 3: Final result reveals extensor tendon maintains a central position over the MCP joint. 


\section{Orthopedics and Rheumatology Open Access Journal (OROAJ)}

Table 1: EDC tendon demonstrated pain-free stability without subluxation on metacarpophalangeal joint flexion, with a full range of motion (ROM) of the metacarpophalangeal (MCP) joint at the latest postoperative evaluation (9 months).

\begin{tabular}{|c|c|c|c|c|c|c|c|c|c|}
\hline \multirow[b]{2}{*}{ Case } & \multicolumn{2}{|c|}{ Preoperative ROM $\left({ }^{\circ}\right)$} & \multicolumn{2}{|c|}{ Postoperative ROM ( $\left.{ }^{\circ}\right)$} & \multicolumn{2}{|c|}{$\begin{array}{l}\text { Wrist flexion compensato- } \\
\text { ry effect }\end{array}$} & \multicolumn{3}{|c|}{$\begin{array}{c}\text { Recurrence } \\
\text { (pain, dislocation, snapping) }\end{array}$} \\
\hline & Ext (lag) & Flex & Ext (lag) & Flex & Pre & Post & Pain & Dislocation & Snapping \\
\hline 1 & 0 & 90 & 0 & 90 & yes & no & no & no & no \\
\hline 2 & 15 & 85 & 15 & 85 & yes & no & no & no & no \\
\hline 3 & 10 & 70 & 10 & 75 & yes & no & no & no & no \\
\hline 4 & 20 & 80 & 20 & $\begin{array}{l}8 \\
0\end{array}$ & yes & no & no & no & no \\
\hline 5 & 0 & 90 & 0 & 90 & yes & no & no & no & no \\
\hline 6 & 20 & 85 & 20 & 85 & yes & no & no & no & no \\
\hline 7 & 15 & 75 & 10 & 80 & yes & no & no & no & no \\
\hline 8 & 10 & 85 & 5 & 90 & yes & no & no & no & no \\
\hline 9 & 0 & 75 & 0 & 80 & Yes & no & no & no & no \\
\hline
\end{tabular}

\section{Discussion}

Traumatic or spontaneous extensor tendon dislocation over the metacarpophalangeal (MP) joint in non-rheumatic hand is a rare condition and occurs most frequently in the middle finger. It results from a rupture of the transverse fibers of the extensor hood on its radial side, allowing ulnar dislocation of the extensor tendon at the level of the MP joint. The extensor tendon at the dorsum of the MCP joint is centralized and stabilized by a complex retinacular system ("dorsal hood") [7]. The sagittal bands are the most important structure of the dorsal hood in the stability of the extensor tendon at the metacarpophalangeal (MCP) level $[8,9]$. Although any of the fingers can be affected, the most commonly injured finger is the middle finger [10]. In traumatic cases, rupture occurs both in the sagittal bands and the dorsal structures of the MCP joint while in spontaneous cases only the superficial layer of the sagittal bands is involved, keeping the dorsal hood and capsule intact [11].

Acute sagittal band and/or ruptures can be successfully treated using closed methods but if extensor tendon instability persists surgical treatment is necessary. Although several surgical techniques have been described to achieve stability of the EDC tendon in chronic injury direct repair of the sagittal band may not be possible due to contracted remnant of the band within the scar tissue. Restoration of sagittal band stability and extensor tendon centralization at the metacarpophalangeal joint by the extensor slip loop technique recreate the physiologic biomechanical forces. This surgical technique presented is relatively simple, reduces the surgical time and only a single skin incision is necessary.

\section{Declaration of Conflicting Interests}

The author(s) declared no potential conflicts of interest with respect to the research, authorship, and/or publication of this article.

\section{References}

1. McCoy FJ, Winsky AJ (1969) Lumbrical Loop Operation for Luxation of the Extensor Tendons of the Hand. Plast Reconst Surg 44(2): 142-146.

2. Ovesen OC, Jensen EK, Bertheussen KJ (1987) Dislocation to Extensor Tendons of the Hand Caused by Focal Myoclonic Epilepsy. J Hand Surg 12(1): 131-132.

3. Rayan GM, Murray D, Chung KW, Rohrer M (1997) The extensor retinacular system at the metacarpophalangeal joint. Anatomical and histological study. J Hand Surg 22(5): 585-590.

4. Kettelkamp DB, Flatt AE, Moulds R (1971) Traumatic dislocation of the long-finger extensor tendon. A clinical, anatomical, and biomechanical study. J Bone Joint Surg Am 53(2): 229-240.

5. Hiroyuki Hayashi, Hideki Shimizu, Shoji Okumura, Kazuhiro Miwa, et al. (2014) Necessary MCP ROM to maintain hand function. Hong Kong Journal of Occupational Therapy 24(2): 51-55.

6. Watson HK, Weinzweig J, Guidera PM (1997) Sagittal band reconstruction. J Hand Surg 22(3): 452-456.

7. Tubiana R, Valentin P (1964) The anatomy of the extensor apparatus of the fingers. Surg Clin North Am Aug 44: 897-906.

8. Rayan GM, Murray D (1994) Classification and treatment of closed sagittal band injuries. J Hand Surg Am 19(4): 590-594.

9. Kichouh M, Vanhoenacker F, Jager T, Van Roy P, Pouders C, et al. (2009) Functional anatomy of the dorsal hood or the hand: correlation of ultrasound and MR findings with cadaveric dissection. Eur Radiol 19(8): 1849-1856.

10. Hakstian RW, Tubiana R (1967). Ulnar deviation of the fingers. The role of joint structure and function. J Bone Joint Surg Am 49(2): 299-316.

11. Ishizuki M (1990) Traumatic and spontaneous dislocation of extensor tendon of the long finger. J Hand Surg Am 15(6): 967-972. 
(C) This work is licensed under Creative

Commons Attribution 4.0 License

DOI: 10.19080/OROAJ.2019.14.555899

\section{Your next submission with Juniper Publishers} will reach you the below assets

- Quality Editorial service

- Swift Peer Review

- Reprints availability

- E-prints Service

- Manuscript Podcast for convenient understanding

- Global attainment for your research

- Manuscript accessibility in different formats ( Pdf, E-pub, Full Text, Audio)

- Unceasing customer service

Track the below URL for one-step submission https://juniperpublishers.com/online-submission.php 